\title{
Artigos
}

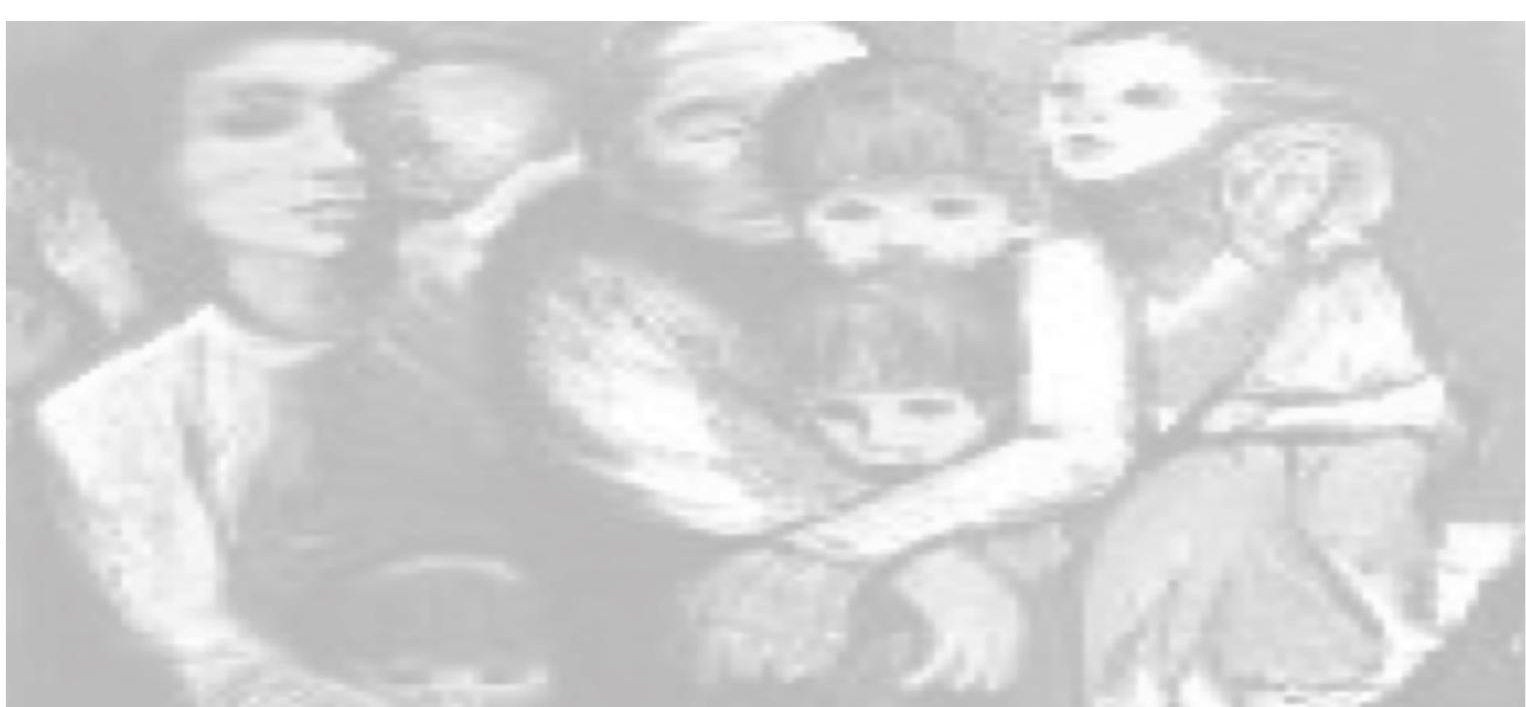





\section{A família contemporânea e a interface com as políticas públicas}

Laisa Regina Di Maio Campos Toledo*

Resumo: O foco deste artigo é a análise do lugar da família contemporânea nas políticas públicas e os desafios postos na garantia dos seus direitos no sistema de proteção social. Parte da caracterização do modelo nuclear de família burguesa, demarcando as principais mudanças afetas a esse grupo social nos últimos cinqüenta anos e as demandas que se configuraram nesse período. No âmbito das políticas públicas destaca a PNAS, sinalizando o lugar da família e as contradições presentes no entendimento da situação de vulnerabilidade e risco social, em relação às exigências postas à família na proteção de seus membros. Finaliza apontando os desafios a serem superados e incorporados no trabalho com famílias na garantia dos seus direitos.

Palavras-chave: família contemporânea, Estado e políticas públicas, sistema de proteção social.

The Contemporary Family and the Interface with Public Policies

Abstract: This article focuses on the analysis of contemporary family's place in public policies and the challenges faced to

Assistente social pela Pontifícia Universidade Católica de São Paulo (PUC-SP), socióloga pela Universidade de São Paulo (USP), doutora em Serviço Social pela PUC-SP e coordenadora do Núcleo de Família e Sociedade do curso de graduação da Faculdade de Serviço Social da PUC-SP. 
assure their rights by the social protection system. It starts by characterizing bourgeoisie's model for the nuclear family, marking the main changes that affected this social group during the last fifty years, as well as the demands configured in this period. As for the public policies, the present work puts light in PNAS, signalizing the family's place and the contradictions found in social's vulnerability and risk comprehension, in relation with the demands put to the families when protecting their members. The article finishes pointing the challenges to be incorporated and overcame in the work with families to guarantee their rights.

Keywords: contemporary family, The State and public policies, social protection system.

\section{Introdução}

Falar de família é apaixonante, envolvente e, de uma forma ou de outra, todos se interessam, sejam leigos ou letrados, justamente pela sua inserção e proximidade íntima com essa forma de agrupamento. Este tema, no entanto, demanda uma série de delimitações, pois sua amplitude favorece os devaneios (tão sedutores) ou pisar em terrenos movediços, principalmente por ser, ao mesmo tempo, tão ambíguo e contraditório.

A respeito, Marisa Corrêa (1982) traz para o debate uma questão que nos ajuda a delimitar o campo de exposição deste artigo. Ancorada na Antropologia, afirma que o tema família já foi bastante debatido, mas não o suficiente, podendo ser identificadas duas posições comuns nas Ciências Sociais:

A primeira é a posição, nunca explicitada, de que a família é um mal a ser combatido, irmã gêmea ou reverso da posição apologética de que a família é a célula mater da sociedade ou refúgio das atribulações do mundo. (...)

A segunda, talvez conseqüência deste tomar partido a favor ou contra a família, é a posição de ignorância em que nos 
encontramos quase todos os que nos interessamos pelo tema, seja pela escassa produção de pesquisas sobre ele, seja porque freqüentemente deixamos de incorporar à nossa reflexão uma perspectiva crítica a respeito da forma como ele tem sido historicamente analisado em nosso país. (Corrêa, 1982, p. 7)

Corrêa abriu uma questão interessante para o debate. De fato, há uma ignorância em relação ao tema, independentemente de quem está "contra ou a favor" da família. ${ }^{1}$ A questão que se coloca - e, de alguma forma, precisa ser tratada na perspectiva crítica - é como a família tem sido analisada historicamente.

Entre tantos ângulos possíveis de tratamento analítico da família, elegemos alguns pressupostos norteadores. Um pressuposto básico quando pensamos em família é a sua inserção no processo de reprodução do cotidiano da vida social. A família reflete e é o reflexo das mudanças que ocorrem na sociedade, o que a torna uma das manifestações importantes da vida social. A família é uma construção humana responsável, basicamente, pelo cuidado e proteção de seus membros, pela socialização e produção de subjetividades. A família tem uma importância vital no modo de organização da sociedade ocidental como primeiro grupo de referência e de pertencimento do indivíduo e como transmissora da linguagem e da ideologia (Reis, 1989).

Pela sua função básica de proteção, a família já é, por princípio, uma parceira do Estado, pois este é, primordialmente, responsável direto pela proteção social. Importa aqui entender - lugar que ela ocupa nessa parceria. Por essa perspectiva, delimitamos o foco deste artigo à análise do lugar da família contemporânea nas políticas públicas e os desafios postos na garantia dos seus direitos no sistema de proteção social.

Esse duelo fez parte da literatura nos anos 70 e 80, quando o modelo de família nuclear burguês foi colocado em xeque e a família foi responsabilizada pelas neuroses do indivíduo. 
Essa questão é atual e não pode ser ignorada no momento em que a família vive uma expressiva e real exposição a situações de vulnerabilidade social, com a diminuição da sua capacidade protetora e a aparente desconstrução do seu modelo referencial.

Outro pressuposto teórico necessário é deixar de tratar a família apenas como uma instituição e incorporar a concepção de sujeito de direitos. ${ }^{2}$ Nessa perspectiva entendemos que as suas demandas devem ser consideradas como a matéria das políticas públicas, campo privilegiado de intervenção do Estado na garantia dos direitos sociais como resposta ao enfrentamento das expressões da questão social.

O ponto de partida é a caracterização e a problematização do modelo de família nuclear burguesa, considerando as questões presentes no debate acerca da família contemporânea. Percorrer esse caminho é necessário para o dimensionamento das demandas postas hoje pela família contemporânea e a análise do lugar da família nas políticas públicas, resgatando a crise do Estado de Bem-Estar Social e os novos desenhos no cenário brasileiro.

Finalizando, indicamos os principais desafios a serem superados e incorporados ao se trabalhar com famílias na garantia dos seus direitos.

\section{A família contemporânea em questão}

De instituição fortificada no modelo nuclear burguês e no território da vida privada, a família vem passando por

\footnotetext{
2 A expressão sujeito de direitos é claramente objetivada na PNAS (2004, p. 35), quando indica que a família também precisa ser cuidada e protegida: "Essa correta percepção é condizente com a tradução da família como sujeito de direitos, conforme estabelece a CF de 1988, o ECA, a LOAS e o EI".
} 
modificações visíveis ao longo das últimas cinco décadas. Afinal, o que fato aconteceu com a família?

De certa forma, não é fácil apontar em uma única questão o que desencadeou essas mudanças. Os autores, em geral, também não se atrevem a ser tão simplistas quando tratam das fronteiras das transformações mais significativas com o advento da modernidade.

A modernidade virou lugar comum nas conversas. Tudo o que acontece, seja desejável ou não, oportuno ou não, ético ou não, enfim, ficou por conta da chamada modernidade, globalização e tantas outras formas de se referir às mudanças aceleradas, por vezes até incompreensíveis e, na maioria das vezes, não totalmente assimiladas. De fato, da nostálgica iluminação cálida do lampião de gás de um São Paulo tranqüilo, no início do século, à era dos satélites que aproximam em minutos as pessoas de qualquer lugar do planeta, muito se exigiu das pessoas, em tão pouco tempo, de sua capacidade de adaptação e constante atualização a um mundo tão agitado por mudanças cada vez mais aceleradas. Mas, se essas exigências se colocam tão vitais, até para a nossa sobrevivência, será que elas se expressam de forma indiscriminada em todas as esferas da nossa vida cotidiana?

Figueira (1987, p. 12) considera que o processo de modernização "não é tão simples assim":

Primeiramente, há várias áreas em que a sociedade parece ter permanecida a mesma, como, por exemplo, os vários setores da população que vivem em estado de miséria e marginalização. Além disso, estamos cada vez mais atentos para o fato de que nem tudo do nosso passado pode ser deixado completamente para trás, que não podemos nos tornar completa e simplesmente 'modernos' da noite para o dia.

A família é um dos temas que merecem ser estudados sob esse cuidado. As ambigüidades em torno da família ganham 
um colorido especial quando confrontadas com o advento da modernidade. Para o redimensionamento desta compreensão cabe, primeiro, entender o processo de formação sóciohistórico da família contemporânea e as implicações atuais com as transformações que ocorreram nos últimos 50 anos.

Constituição histórica da família contemporânea e principais características

Reis (1995) oferece o percurso histórico da família contemporânea. O padrão dominante de família em nossa sociedade teve suas origens em meados do século XVIII, no interior da burguesia européia e, no século XIX, tornou-se modelar de forma que se manteve quase inalterado até meados do século XX. Deriva de um modo de organização social em que privacidade, domesticidade, cuidados maternos e relações íntimas entre pais e filhos foram necessários para a reprodução de uma ordem assentada na exploração da força do trabalho e na acumulação do capital.

O sentimento de família (Áries, 1978), forjado nesse período, concorreu para a sedimentação desse modelo bem como a reprodução ideológica do capitalismo. Ou seja, o bem-estar da família e sua importância foram invocados constantemente como necessários para que o trabalhador tolerasse a exploração da sua força de trabalho, a alienação e a humilhação social.

São ingredientes básicos do modelo nuclear burguês a privacidade e o fechamento em torno do relacionamento básico entre pais e filhos, voltados, prioritariamente, para um projeto de realização individual marcado pela perspectiva de ascensão social e superação dos limites vividos pela geração anterior.

O território que legitima o lar burguês é o espaço do privado ou o espaço da intimidade contraposto ao espaço do 
público, em geral representado pela hostilidade e competição. A família passa a ser representada, dessa forma, como o lugar das relações íntimas, de lazer, de paz, de tranqüilidade, idealmente marcada como um refúgio solidário em oposição ao mundo sem coração (Poster, 1979; Lash, 1991).

A família representa o espaço do privado, da intimidade, da casa, do lar, e é representada em relação e oposição ao espaço do público, da rua, da exterioridade. Diversos autores já se debruçaram sobre o estudo da intersecção entre os espaços do público e do privado, e a maioria deles reconhece que há uma cisão na representação desses dois espaços.

Da Matta (1987) analisa como o mundo da rua é o da luta pela vida e o da casa é o do reconhecimento das pessoas. É na família, na casa, que as pessoas encontram a referência e o apoio para enfrentar as adversidades do cotidiano.

Para Habermas (1984), a esfera íntimo-privada é o espaço do investimento maior de sentimentos afetivos que, em regra geral, são mais discretos no trabalho, onde domina a impessoalidade, a civilidade. Sennett (1993, p. 31) também mostra essa cisão ao definir que o público é "(...) uma região da vida social localizada em separado do âmbito da família e dos amigos íntimos (...)". Afirma, ainda, que na cultura do individualismo ocorreu o declínio da vida pública, uma vez que o eu constantemente invade o espaço do outro e as pessoas se resguardam uma das outras.

Lash (1991), contrariando a tese de Sennett, defende que a vida familiar e o espaço do privado é que foram devassados no espaço que Ihes eram próprios. Segundo Lash (1991), o indivíduo narcisista foi fabricado pela violação capitalista daquilo que a família burguesa tradicionalmente sempre quis preservar: o espaço do privado como o refúgio no mundo impessoal. Por outro lado, a cultura narcisista, fundada pela 
modernidade, passou a justificar os indivíduos que agem por interesses privados, muitas vezes às custas do cerceamento dos interesses dos outros.

O sentimento de família media as relações entre os espaços do público e do privado, intensificando o vínculo afetivo entre seus membros como uma defesa contra o mundo exterior e, ao mesmo tempo, demarcando o território de pertencimento e manifestação dos afetos.

Outra característica da família nuclear burguesa é a assimetria e hierarquia pelos critérios de sexo e idade, isto é, a "conversão de uma diferença e de uma assimetria numa relação hierárquica de desigualdade com fins de dominação, de exploração e de opressão, (...) a conversão dos diferentes em desiguais e a desigualdade em relação entre superior e inferior" (Chauí, 1984, p. 35). Amparada pela ideologia do patriarcado, a família legitima o poder e supremacia do homem sobre a mulher e dos adultos sobre as crianças. Nesse sentido, é inegável o poder da família sob o ponto de vista da sua tarefa disciplinadora e de controle sobre os seus membros.

Outra característica: a divisão sexual do trabalho bem definida, atribuindo-se ao homem a tarefa de provedor e à mulher a de cuidadora. Cabe ao homem enfrentar as "agruras" do mundo do trabalho e à mulher os "deleites" do lar. Nessa perspectiva a valorização da maternidade foi essencial para o lar ser considerado um local aprazível. Como conseqüência, coube à mulher uma posição central na dinâmica afetiva da família, o que configurou a matrifocalidade ou centralidade na mãe.

Outra característica é o caráter monogâmico da relação conjugal, assentado no controle da sexualidade sobre a mulher como garantia de legitimidade da prole para a herança da propriedade privada (Engels, 1970), apesar de ser admissível 
a dupla moral sexual. Ou seja, o controle da sexualidade recai sobre a mulher, enquanto do homem é aceitável o exercício da sexualidade fora do casamento.

Finalmente, a característica mais exaltada quando se pensa nesse modelo de família refere-se às relações afetivas balizadas pelo amor incondicional. Para D'Incao (1989, p. 10), a família nuclear burguesa

caracteriza-se por um conjunto de valores, que são o amor entre os cônjuges, a maternidade, o cultivo da mãe como um ser especial e do pai como responsável pelo bem-estar e educação dos filhos, a presença do amor pelas crianças e a compreensão delas como seres em formação e necessitados, nas suas dificuldade de crescimento, de amor e de compreensão dos pais.

Concluindo, podemos citar Romanelli (1995, p. 75 e 78) que, resumidamente, define o modelo nuclear de família:

Em linhas gerais, esse modelo de família (nuclear) tem como atributos básicos: uma estrutura hierarquizada, no interior da qual o marido/pai exerce autoridade e poder sobre a esposa e filhos; a divisão sexual do trabalho bastante rígida, que separa tarefas e atribuições masculinas e femininas; o tipo de vínculo afetivo existente entre os cônjuges e entre esses e a prole, sendo que neste último caso há maior proximidade entre mãe e filhos; o controle da sexualidade e a dupla moral sexual.

Essa diferença no relacionamento entre os filhos e seus pais e suas mães era compatível com o modelo hegemônico de família nuclear que atribuía ao pai a condição de provedor financeiro do consumo doméstico e à mãe a responsabilidade pela socialização da prole e pela doação do afeto.

\section{As principais mudanças}

Analisando a família em relação ao movimento avassalador das mudanças do século XX, os sinais são visíveis. 
Desde as suas origens, podemos indagar o que se alterou, principalmente nos últimos 50 anos.

De tradição eminentemente patriarcal, a família brasileira foi tratada pela primeira vez por Gilberto Freyre em Casa Grande \& Senzala, escrito em 1933 e considerado um marco dos estudos sobre a família no Brasil. ${ }^{3}$ Freyre se ateve à família do período colonial, introduzindo a referência básica ao modelo patriarcal imposto pela colonização de base européia e adaptado às condições sociais da época, ou seja, um país latifundiário e escravagista. Esse tipo de família foi uma das matrizes de um modelo que se sedimentou como hegemônico, mas ocultou uma pluralidade de formas alternativas de organização familiar, com a marca de uma flexibilidade maior, que viveu à "margem", como desvio da norma, tentando se adaptar aos limites do idealizado.

Identificada com uma estrutura forte, extremamente centralizadora e autoritária, a família patriarcal, vista como uma instituição normatizadora, vigilante e disciplinar, organizava as formas de reprodução e reposição da vida social ao lado da Igreja e de valores morais, mantendo-se basicamente inalterada até o século passado. No Brasil, esse modelo só foi colocado em xeque pelo processo de modernização desencadeado na década de 30 e consolidado após os anos 50.

Nas décadas seguintes, os pilares que sustentavam esse modelo foram abalados ao ser colocada em dúvida a sólida firmeza da importância da família como célula mater da sociedade ante o debate em torno da saúde mental dos

3 Na literatura, as famílias dos escravos são tratadas diferencialmente e invocadas, particularmente, quando se analisa as chamadas famílias pobres ou de camadas populares de baixa renda. Há uma tese corrente que o senhor de engenho não permitiu a formação de famílias e do sentimento de família entre os escravos para facilitar a separação de pais e filhos por ocasião da sua comercialização como mercadoria. Por essa tese tenta-se explicar a aglutinação da família em torno da mãe e a "marginalização da figura do homem" nessas camadas sociais (Szymanski, 1992). 
seus membros e das neuroses desenvolvidas na família. A chamada "crise" da organização clássica da família teve como marco histórico a revolução dos costumes dos anos 60 e, mais particularmente, os alardes do movimento feminista que instigaram a saída das mulheres para o mercado de trabalho.

As mudanças, no entanto, não apontaram para o fim da família enquanto grupo social e tampouco para a superação do modelo nuclear burguês. Ou seja, a importância da família enquanto "célula mater" da sociedade continuou em evidência, apesar da "crise" do modelo nuclear, monogâmico, patriarcal e burguês.

Vários autores defendem a manutenção da família em outros patamares. Heller (1987), analisando a possibilidade de implosão da família no Estado de Bem-Estar Social, é enfática ao afirmar a sua importância na garantia da "intimidade e da segurança emocional, sem as quais os seres humanos ficam condenados a uma vida inferior, ao isolamento e às neuroses". Seu principal argumento incide na tese de que:

Se se tem um lar não se pode ser livre de todo. Mas, se não se tem um lar para onde retornar, onde encontrar os amigos, onde se é conhecido e compreendido, onde se pode relaxar completamente, não se pode ser emocionalmente seguro. (Heller, 1987, p. 28)

A autora conclui afirmando que "se queremos fazer do mundo a nossa casa, devemos ter uma casa no mundo", o que significa que a família ainda é importante, seja qual for o seu formato, como coadjuvante na busca da felicidade, valor maior a que o homem deve aspirar, mas sem sacrifícios, sem opressão e sem exploração. (Heller, 1987, p. 28).

Como já nos posicionamos, não se trata exatamente de um duelo entre "o contra" e o "a favor". A família é inegavelmente 
importante e necessária no modo de organização capitalista, bem como referência para a segurança emocional dos seus membros (Heller, 1987). Segundo Mioto, Campos e Lima (2006, p. 178) "a família não é uma construção privada, mas também pública", com um "papel importante na estruturação da sociedade em seus aspectos políticos e econômicos, além da capacidade de produção de subjetividades".

A complexidade da vida nas grandes metrópoles intensificou a representação do mundo hostil e exigiu que a família se protegesse no seu interior. Isso significou o acirramento do isolamento e da privacidade, visíveis, inclusive, pela necessidade de proteção contra a violência externa, com reflexo no aumento da condição de segurança nos domicílios, a colocação de grades nas janelas, a contratação de segurança privada etc. Ao mesmo tempo, a família se dispersou em inúmeras atividades fora dos limites da casa. Novas necessidades foram criadas, exigindo das crianças, por exemplo, prontidões em outras direções além do lúdico protegido pelos olhares materno. Essa contradição colocou em patamares alarmantes a tarefa de proteção e cuidados, aqui particularizada na dimensão da segurança, carregada de medos e tensões no monitoramento do dia-a-dia dos filhos.

As mudanças da família, no entanto, não anularam os significados estruturados a partir do modelo tradicional, mesmo quando apontam para novas possibilidades. Vários autores, como Szymanski (1987), Figueira (1987) e Sarti (1996), analisam as ambigüidades presentes nas representações acerca da família. Destacamos Szymanski (1987), que distingue a família pensada da família vivida. A família pensada baseia-se no modelo idealizado de família nuclear e a família vivida é a possibilidade dada pelos arranjos no real. Quando o modelo idealizado não corresponde à possibilidade vivida, o resultado é o sofrimento por se sentir fora da normalidade. 
O desejável, apesar das mudanças, ainda é a velha fórmula conhecida da família nuclear, heterossexual, monogâmica e patriarcal, vendida pela mídia por meio da imagem do casal feliz numa união estável, filhos amorosos, vivendo o cotidiano com divisões sexuais de papéis e obrigações claramente definidas, e todos confortavelmente instalados numa casa com flores nas janelas e recendendo ao cheiro da comida farta $e$ recém-saída do fogão. Conflitos são permitidos nesse roteiro, mas nada que o amor e a solidariedade entre seus membros não possa resolver.

O modelo ideal de família ainda está sedimentado no imaginário coletivo e subsiste, muitas vezes, como um sistema de controle que se expressa por meio dos mecanismos de preconceito, exclusão e discriminação. Também, se ele subsiste no plano das representações sociais é porque representa, sobretudo, um modelo ainda legitimado e necessário.

Outro aspecto visível foi quanto às conquistas na luta pela emancipação feminina, particularmente nas frentes da participação no mercado de trabalho e no espaço público. Os anos 60 ofereceram um cenário fértil para as mudanças, e o movimento feminista foi mais uma forma de resistência que também encontrou um espaço visível entre outras tantas que eclodiram nesse período (Toledo, 1995). De movimento de minorias, ganhou fôlego para além das passeatas e manifestações públicas, foi institucionalizado e teve reivindicações incorporadas nas políticas públicas, principalmente no campo da violência, da saúde e dos direitos reprodutivos. Com o advento da pílula, a mulher conquistou o controle de sua função procriadora, bem como o direito a ter prazer.

A mulher denunciou a privação alienante do espaço do privado e lutou pela conquista dos territórios no mercado de 
trabalho, antes quase que exclusivo do homem, para além das ocupações extensoras do lar. A privação do privado foi denunciada como a violência não-vista, garantida pelas instituições sociais.

Ao prescrever para a mulher um papel passivo e submisso, a sociedade cria espaço para o exercício da imposição. A socialização tradicional impõe às mulheres que abdiquem de certas profissões, desejos, prazeres e que fiquem confinadas a certos ambientes. Isso, porém, não é entendido como violência, embora seja uma violência institucionalizada. A denúncia e a consciência desse tipo de violência só foi possível porque já existe uma prática contrária, ou seja, já se abriu espaço para a discordância, uma vez que o que era o reino do privado de cada um passou a ser público e transformado em questão política. Revela-se o lado não-manifesto (reprimido) das situações cotidianas. (Cardoso, 1985, p.18)

Apesar das conquistas, a mulher teve o encargo de mais responsabilidades e a matrifocalidade ganhou contornos ainda mais visíveis. A dupla jornada de trabalho e a necessidade de uma rede de creches são exemplos do preço da sua conclamada emancipação. Ainda, registramos a questão dos salários mais baixos (Amaral; Toledo, 2001) e a quase inexistente oferta de uma rede de serviços públicos no amparo à infância, obrigando a mulher a recorrer a estratégias diferenciadas, que acabam sendo de sua inteira iniciativa e responsabilidade.

Na mesma direção, destacamos o aumento de famílias chefiadas por mulheres, que confirmam a nucleação da família em torno da mulher. Adquirir autonomia e se emancipar por meio da participação no mercado de trabalho era uma de suas aspirações, mas assumir a total responsabilidade como provedora da família, ou principal provedora, não se apresentava como um ponto da pauta de suas reivindicações.

Hoje, a mulher chefe de família é um fato mais do que visível (Carvalho, 1998; Toledo, 2004). Os motivos são muitos: 
da situação de abandono ao de viúva prematura por causa da violência urbana, passando pela ausência do cônjuge que saiu em busca de trabalho ou simplesmente abandonou a casa, mães solteiras e até aquelas que arriscaram pôr em prática o projeto de "produção independente". Mas, seja qual for o motivo, segundo dados do Seade (1994), na Região Metropolitana de São Paulo, em estudo de 1990, 17,3\% das famílias eram chefiadas por mulheres. Esse resultado ganha outra dimensão quando se considera o perfil socioeconômico das famílias da RMSP (Região Metropolitana de São Paulo). Dos quatro agrupamentos definidos para o estudo, no Grupo $D$, no qual as famílias "se encontram na situação mais desfavorável quanto ao nível de instrução, inserção no mercado de trabalho e disponibilidade de renda" (Seade, 1994, p. 6), mais de $25 \%$ das famílias são chefiadas por mulheres. Esses dados já ganharam outros contornos após uma década. Hoje, mais de $30 \%$ é um resultado mais próximo da realidade.

A despeito desse tipo de arranjo, o modelo de família nuclear burguês ainda persiste quando pensamos em chefe de família. Mesmo que a mulher esteja assumindo a condição de provedora do domicílio, a posição de chefe de família é conferida moralmente ao homem, pois implica uma posição de hierarquia e poder bastante privilegiada num modelo que ainda sobrevive, embora recaiam sobre a mulher as responsabilidades da chefia.

De dona de casa, a mulher passou a dona da casa, vivendo cotidianamente inúmeros embates. Se várias possibilidades se colocam diante de um "modelo em crise", esta, sem dúvida, é expressivamente uma delas e vem a público como uma demanda a ser enfrentada e contemplada nas políticas públicas.

A autoridade paterna afrouxou-se, passando a ser contestada e até negociada, embora ainda perdurem relações 
autoritárias e opressivas entre pais-filhos e marido-mulher (Romanelli, 1995).

A criança foi fortalecida e ganhou uma estatura nunca antes testemunhada pela história. A sua sociabilidade foi ampliada pela extensão da função socializadora da família a outros agentes e instituições sociais, como a escola, por exemplo. Também o Estatuto da Criança e do Adolescente (ECA) sacramentou o reconhecimento da criança e do adolescente enquanto sujeitos de direitos. Contraditoriamente, a criança ocupou uma posição de centralidade e ganhou poder de influência, em relação ao consumo, por exemplo. Foi investida de autoridade, desafiando os pais e educadores, e hoje essa questão configura uma demanda, implícita no debate entre limite e afeto, ou amor e disciplina. Contraditoriamente, também, os índices de trabalho infantil aumentaram, impondo a essas crianças a precocização do mundo adulto e responsabilidades além dos seus limites.

A fragilização dos vínculos familiares se acentuou com as separações e divórcios. O casamento eterno e indissolúvel ficou submetido às regras e intensidade das relações amorosas, o que implicou substituir a clássica frase "até que a morte vos separe" por "até que o amor dure". O valor básico que sustenta as separações, segundo Velho (1985), é a felicidade e a realização individual, "que permite enfrentar, com um mínimo de segurança, os dissabores e tempestades da quebra da aliança”.

O autor aponta para o fato de que nas separações "há diferenças significativas entre homens e mulheres. Estas, em princípio, estão mais sujeitas à acusação e estigmatização", baseadas fundamentalmente no julgamento da moral e na vigília da honra. Sem um homem para exercer essa responsabilidade, as mulheres ficam mais fragilizadas e sujeitas à discriminação. 
Salem (1980) enfatiza que há um temor por parte das mulheres em torno da possibilidade de separação, denominado o "espectro do abandono".

Numa situação de separação, em geral, o sentimento da mulher é de fracasso (Salem, 1980). E por vários motivos. Talvez o mais forte é o de não ter sido capaz de manter a família unida, mesmo que isso lhe custasse o sofrimento da violência doméstica, da humilhação diária e do trabalho da dupla jornada. No modelo tradicional de família, a mulher é, particularmente, a maior responsável pela manutenção do casamento. Apesar da monogamia, por exemplo, ser um traço constitutivo desse modelo, a dupla moral sexual é tolerada pela mulher em nome da preservação da família e da figura paterna. Instala-se, assim, um certo "pacto conjugal" necessário para a manutenção da família. Se rompido pela mulher, esta é, invariavelmente, penalizada e acusada como única responsável por macular os sagrados laços do casamento, abençoado pela Igreja e pelos mandamentos divinos. Por isso, a exigência de fortes doses de tolerância às humilhações e aos maus tratos. $O$ sentimento de fracasso da mulher, portanto, alimenta-se e é alimentado pela acusação e estigmatização, dado que os avanços e conquistas do movimento feminista não suavizaram as culpas da mulher pelo casamento desfeito. Segundo Velho (1985), essa questão hoje é contornada nos segmentos mais intelectualizados das camadas médias pela chamada cultura psi que, por meio da psicanálise ou terapias, ajuda a enfrentar os riscos e custos envolvidos; no entanto, trata-se de uma alternativa disponível apenas para uma elite e não para toda a sociedade.

A transformação da intimidade e do erotismo abalou a moral e os costumes vinculados à sexualidade. $\mathrm{O}$ fato foi considerado uma "revolução", entendida por Heller (1982) e Giddens (1992) como um dos patamares da modernidade. 
Novas configurações, arranjos ou diferentes formas de organização familiar ganharam visibilidade, especialmente nas grandes metrópoles, e hoje, sem dúvida, é cada vez maior a aceitação de famílias que apresentam outras composições, como as monoparentais, formadas por parceiros homossexuais, ou, até, as que se mantêm como família mesmo sem haver coabitação com o parceiro amoroso. Os arranjos familiares hoje se constituem uma resposta às novas demandas colocadas pela modernidade, mas a forma como a família as assume no plano do real ainda é entendida como a divergente, e não a possível. Há um consenso de que a modernidade é desejável, mas não pode ser uma ameaça a um ideal de segurança afetiva num mundo cada vez mais adverso. Assim, os novos arranjos são tolerados como inevitáveis, mas, ao mesmo tempo, negados e entendidos como desvios da norma, ativando mecanismos perversos de controle e preconceito. A diversidade de arranjos familiares implica o tratamento da família no plural, ou seja, não podemos mais nos referir à família, mas às famílias.

Outra mudança significativa foi a emergência para o público de aspectos em que a dinâmica da família não dava conta de sua tarefa primordial, ou seja, o cuidado e a proteção de seus membros. Contraditoriamente, a intensificação da privacização do privado e do isolamento da família foi acompanhada pela publicização do privado e o tratamento do privado como uma questão política. $O$ porto seguro refere-se à natureza de um espaço que só recentemente vem sendo desmistificado. $\mathrm{Na}$ verdade, essa questão acentua uma falsa cisão apoiada no direito discutível da privacidade. $O$ espaço da intimidade sempre foi, por excelência, o espaço do privado e privativo, restrito estreitamente e estritamente à família. Invadir e violar o espaço da intimidade era quase um tabu, pois significava a apropriação de um espaço onde a soberania do indivíduo era inviolável. Ou seja, o reconhecimento da cidadania é muito 
mais efetiva no espaço do privado do que no público por ser mais visível o campo de interferência e poder. Nessa linha de raciocínio, para Kowarick (1991), o cidadão é considerado "sub-cidadão público e cidadão privado": o cidadão público deslocou-se para dentro de casa, ou seja, o protagonismo possível de cidadania passou a ter contextualidade no espaço do privado e não mais no público.

No entanto, o espaço da intimidade é bastante controverso, pois se apresenta contaminado pelas mais diversas contradições que se objetivam, particularmente, nas diversas formas de manifestação da afetividade e do poder. São verdadeiros embates afetivos marcados por ambigüidades diversas. Primeiramente, esse espaço se beneficia e é protegido pelo direito do cidadão à privacidade, garantindo a sua inviolabilidade. É em nome da felicidade que o espaço da intimidade é proclamado como o espaço do refúgio no mundo impessoal, mas, ao mesmo tempo, o "porto seguro" para a manifestação e amplificação dos afetos, conflitos, discórdias, sofrimentos e violência. O espaço da intimidade pode ser até um verdadeiro campo de batalha sangrento e violento, mas não anula a sua representação como um porto seguro para a expressão dos sentimentos, sejam eles quais forem, até os sentimentos mais destrutivos que possamos conhecer. Nesse sentido, muitas atrocidades já foram cometidas em nome do amor e do respeito à hierarquia e permaneceram encobertas pelo pacto do silêncio, da privacidade e, até, da vergonha quando expostas.

A visibilidade da violência doméstica e familiar, por exemplo, é um fato recente. A violência é uma das formas de manifestação do poder patriarcal exercido na família (Saffioti, 2004; Toledo, 2007). Só recentemente, com a denúncia dos movimentos e dos estudos acerca da violência doméstica contra mulheres e crianças, em suas mais diversas manifestações, 
é que o poder público começou a olhar para o espaço da intimidade, inclusive institucionalizando essa expressão da questão social, embora de forma ainda insuficiente pelo volume das ocorrências. Os movimentos feministas e de defesa dos direitos humanos, entre eles os das crianças, adolescentes e idosos, vêm denunciando essa situação insistentemente, reivindicando a institucionalização do seu enfrentamento.

Nessa linha de raciocínio, Lash (1991) analisa os efeitos eticamente perversos do refúgio dos sentimentos no âmbito do espaço da intimidade, como o narcisismo, por exemplo.

Giddens (1993) já parte de outro ângulo, quando considera que a intimidade é um espaço importante de reprodução da vida cotidiana, tão fundamental quanto o espaço do público no processo de transformação social e na luta pela emancipação. Toledo (1995) considera que esse espaço apresenta possibilidades de emergência de demandas reais para alimentar o debate público em torno dos direitos sociais, podendo ser considerado como o um "espaço de militância", pois no espaço da intimidade também se travam as lutas pela emancipação humana.

O espaço da intimidade, nas últimas décadas, indiscutivelmente, foi um dos cenários para a luta da emancipação da mulher, escondido dos holofotes públicos, mas tão dinâmico quanto os movimentos sociais. Contraditoriamente, também foi o cenário de práticas opressoras, mas, sendo a consciência dessa situação mais evidente, a subalternidade entendida como "natural" já não vem ganhando adeptos.

\section{O lugar da família nas políticas públicas}

A família foi recuperada como coadjuvante do Estado no sistema de proteção social na esteira da crise do Estado de 
Bem-Estar Social. Até então era entendida como uma instituição afeta ao território privado dos afetos com funções de proteção social restritas diante da tarefa do Estado como responsável por essa tarefa. Autores que analisam as políticas de proteção social e de defesa dos direitos do indivíduo implementadas pelo Estado de Bem-Estar Social chegaram até a sugerir a possibilidade da implosão da família. Entre eles, Heller (1987) anteviu o fim desse agrupamento social pelo fato de o Estado ter tomado para si as atribuições da família.

A família também era elegível como alvo da intervenção estatal quando não cumpria com as suas responsabilidades, sendo diretamente culpabilizada pela situação de pobreza, transgressão social, negligência nos cuidados com crianças, adolescentes eidosos. Os direitos eram direcionados elegitimados ao indivíduo. A família era revestida fundamentalmente de deveres, factível de ser punida. A responsabilidade, bem como a punição, recaíam mais particularmente sobre a mulher, incidindo, com freqüência, sobre a perda do pátrio poder e resultando na institucionalização dos "menores" quando o Estado, por meio dos seus agentes, entre eles o assistente social, julgasse a família incapaz de cuidar e proteger os seus membros.

Lash (1991, p. 37) aponta com propriedade o quanto a intervenção de especialistas, particularmente nos EUA na década de 20, foi legitimada às custas da família julgada incapaz diante da onipotência do Estado na sua tarefa vigilante e protetora do direito do indivíduo. A falência das famílias era atribuída às falhas nos princípios morais, que "constituíam as causas subjacentes do crime e da desorganização social", justificando, assim, os termos "família desorganizada", "família desetruturada", "família incompleta" etc. Estava instalada a patologia social como objeto de intervenção das profissões assistenciais em seu período de institucionalização, entre elas 
o Serviço Social. Essa perspectiva foi trazida duas décadas depois para o Brasil, incrementando a então vigente visão, moralmente comprometida, dos assistentes sociais desde fins da década de $30 .^{4}$

No caso do Brasil, segundo Mioto, Campos e Lima (2006, p. 170),

o processo sócio-histórico de constituição do sistema estatal de proteção social foi marcado profundamente pela estrutura desigual socioeconômica, determinante de uma lógica de exclusão social. (...) Considera-se, portanto, que o Estado brasileiro nunca chegou a consolidar um sistema de proteção social como o Estado de Bem-Estar Social europeu.

Ainda, segundo as mesmas autoras, a "família brasileira, longe de ter sido esvaziada de suas funções, sempre esteve sobrecarregada". No entanto, apesar dessa condição, a família foi um tanto quanto culpabilizada quando não correspondia ao que dela era esperado no âmbito do Estado de Bem-Estar Social.

Com a gradativa orientação social para o chamado Estado mínimo, a família, alvo das políticas públicas, é eleita a partir do critério de vulnerabilidade social, isto é, quando está ameaçada a sua capacidade protetora e provedora. A polêmica, no entanto, instala-se quando nos debruçamos sobre o que se entende por famílias vulnerabilizadas. A partir da análise das transformações sociais que recaíram sobre a família, podemos adentrar no debate acerca da vulnerabilidade social.

A primeira instância de vulnerabilidade da família refere-se à sua tão enfatizada "natureza" como núcleo solidário, extensivo, inclusive, para as relações intrafamiliares.

4 Esse olhar sobre a família resistiu e se manteve vigoroso até recentemente, sendo comum encontrarmos as expressões "família desestruturada" ou "família desorganizada" nos laudos jurídicos. 
Referimo-nos à "moral dos pobres" (Sarti, 1996), que favorece a criação de redes solidárias entre os membros de uma família nuclear e extensa. No entanto, essa rede se objetiva fundamentalmente em famílias numerosas. Nas últimas décadas, as famílias diminuíram com a queda da taxa de fecundidade das mulheres, o que implicou famílias menores e com uma rede de solidariedade mais comprometida. Famílias menores também são mais sensíveis às situações de crises, morte e desemprego.

Outro aspecto refere-se à complexização das demandas das famílias, resultante das transformações ocorridas na família, dos aspectos diferenciados que as diferentes fases da vida de cada membro da família exigem, dos desafios advindos do meio social e das formas de lidar com as transformações que ocorreram no campo das relações homem/mulher e pais/filhos. Incluímos nesse espectro a mudança no caráter do vínculo do casamento e a maior convivência entre as gerações por conta do aumento de expectativa de vida e das necessidades de cohabitação pela pobreza. Ou seja, aumentou a responsabilidade das famílias no enfrentamento dos riscos sociais, na capacidade de proteção contra a violência, no sofrimento com a fragilização dos vínculos afetivos, na insegurança diante do desemprego, entre outros. Exige-se das famílias uma criatividade exaustiva para repor as condições de sobrevivência e enfrentar as dificuldades do cotidiano.

Porém, a vulnerabilidade mais visível se instalou a partir do modelo de desenvolvimento econômico adotado pelo Estado, que aprofundou o processo de empobrecimento das famílias, a migração para as cidades, o ingresso de grande contingente de mulheres e crianças no mercado de trabalho e a diminuição de postos de trabalho. Em contrapartida, adotou uma política de inspiração neo-liberal que redundou na perda gradativa da eficiência do setor público na prestação 
de serviços, restringindo para as soluções assistenciais e compensatórias os processos de atenção à família. ${ }^{5} \mathrm{~A}$ partir dessa perspectiva, a família passou a ser responsabilizada diretamente pela proteção de seus membros como sujeito coletivo e parceira solidária do Estado, visível na legislação vigente ${ }^{6}$ e ocupando posição central enquanto destinatária das políticas públicas, particularmente na saúde (Programa Saúde da Família, cuidados com a maternidade e primeira infância) e assistência social (Política Nacional de Assistência Social PNAS $\left.^{7}, 2004\right)$.

No âmbito da assistência social, a família é entendida como "um conjunto de pessoas que se acham unidas por laços consangüíneos, afetivos e/ou de solidariedade" (PNAS, 2004, p. 35). A definição de família ampliada, ancorada nas pessoas que residem no mesmo domicílio para além dos laços de consangüinidade é um avanço, mas também é discutível quando, contraditoriamente, essa concepção é usada como base para o cálculo do Benefício da Prestação Continuada (BPC) da LOAS, ${ }^{8}$ legitimando a lógica da potencialização do recurso quando se vive em família.

Segundo a PNAS (2004, p. 11), as três vertentes de proteção social são: as pessoas, as suas circunstância e, dentre elas, seu núcleo de apoio primeiro, isto é, a família”. Valorizada

5 Segundo Mioto (1997, p.123), "por processos de atenção à família estamos entendendo todo o conjunto de ações e propostas que interferem na vida familiar e podem ser articulados em três pilares, a saber: as políticas sociais, o modelo assistencial vigente nos espaços institucionais, as demandas específicas de cada grupo familiar".

6 A responsabilidade da família nos cuidados e proteção dos seus membros se expressa claramente na Constituição Federal (1988), no Estatuto da Criança e Adolescente (1990), na Lei Orgânica da Assistência Social (1993) e no Estatuto do Idoso (2003).

7 A PNAS expressa a materialidade do conteúdo da Assistência Social como um pilar do Sistema de Proteção Social Brasileiro no âmbito da Seguridade Social.

8 Na LOAS, a família é uma unidade mononuclear, vivendo sob o mesmo teto, cuja economia é mantida pela contribuição de seus integrantes. A família passa a ser entendida como sujeito de direitos, conforme estabelece a CF de 1988, o ECA, a LOAS e o EI. 
como primeiro núcleo de apoio, a família é entendida como um espaço de segurança, aqui objetivado pelo direito ao convívio ou vivência familiar: "a proteção social deve garantir as seguintes seguranças: segurança e sobrevivência (de rendimento e de autonomia); de acolhida; de convívio ou vivência familiar" (p. 25). A eleição do convívio familiar como uma segurança reitera as posições clássicas da família como um porto seguro, reinstalando, portanto, uma das características do modelo de família burguesa.

Na PNAS, o critério de vulnerabilidade social é usado para a eleição e dimensionamento do público usuário da Política de Assistência Social:

[...] cidadãos e grupos que se encontram em situações de vulnerabilidade e riscos, tais como:

- famílias e indivíduos com perda ou fragilidade de vínculos de afetividade, pertencimento e sociabilidade;

- ciclos de vida;

- identidades estigmatizadas em termos étnico, cultural e sexual;

- desvantagem pessoal resultante de deficiências;

- exclusão pela pobreza e/ou no acesso às demais políticas públicas;

- uso de substância psicoativas;

- diferentes formas de violência advinda do núcleo familiar, grupos e indivíduos; inserção precária ou não inserção no mercado de trabalho formal e informal; estratégias e alternativas diferenciadas de sobrevivência que podem representar risco pessoal e social. (PNAS, 2004, p. 27)

No exposto, a situação de vulnerabilidade e risco social foi objetivada em um conjunto de indicadores relativos às 
adversidades que atingem inúmeras famílias como expressões da questão social. De certa forma, o entendimento de situação de vulnerabilidade e risco social contém o mérito do reconhecimento das demandas postas pelas famílias no enfrentamento do seu cotidiano:

Por reconhecer as fortes pressões que os processos de exclusão sociocultural geram sobre as famílias brasileiras, acentuando suas fragilidades e contradições, faz-se primordial sua centralidade no âmbito das ações da política social, como espaço privilegiado e insubstituível de proteção e socialização primárias, provedora de cuidados aos seus membros, mas que precisa também ser cuidada e protegida. (PNAS, 2004, p. 35)

O pressuposto acima seria correto se não estivesse atrelado a um sistema de proteção social restrito e insuficiente, isto é, quando aponta para uma Política de Assistência Social que elege os indivíduos ou grupos sociais no limite das condições de sobrevivência. Mesmo partindo do entendimento da assistência social como um "conjunto de ações e atividades desenvolvidas nas áreas públicas e privadas, com o objetivo de suprir, sanar ou prevenir, por meio de métodos e técnicas próprias, deficiências e necessidades de indivíduos ou grupos quanto à sobrevivência, convivência e autonomia social" (Mestriner, 2001, p. 16), temos que lutar pela ampliação da ação do Estado para programas de atenção e não só de proteção.

Por outro lado, o entendimento de situação de vulnerabilidade e risco social não pode ser aplicado apenas à situação de pobreza, pois exclui outros segmentos sociais que igualmente precisam ser cuidados e, portanto, por princípio, nega o caráter universal dos direitos sociais. A questão da violência doméstica e familiar, por exemplo, atravessa as diversas camadas sociais e é reconhecidamente um caso de direito no âmbito da proteção social. Ou seja, o mesmo Estado que reconhece os parâmetros necessários de proteção 
social à família, justamente pelo conjunto das determinações sociais que a afetam, trata de forma insuficiente essa questão. Caberia aqui, seguramente, a devida ampliação das políticas públicas para além da assistência social, entendendo o caráter universal dos propósitos de um Estado de direito para a efetiva objetivação da família como parceira solidária.

A realidade vivida pelas famílias impõe inúmeras demandas que exigem um leque mais amplo de proteções. Repomos, sem dúvida, a necessidade de ações mais efetivas para a efetivação, manutenção e ampliação dos direitos sociais na proteção de grupos em situação de vulnerabilidade social, tendo sempre por horizonte superar os efeitos do processo de exclusão social que atingem diretamente os segmentos mais empobrecidos. Ou seja, o privilegiamento das famílias com maior número de carecimentos é necessário, mas não podemos reduzir o nosso horizonte apenas ao mínimo. As famílias estão precisando ser cuidadas, pois, solitariamente, estão enfrentando pressões e não estão dando conta das transformações que as atingiram.

Contraditoriamente, não podemos deixar de sinalizar positivamente os avanços da PNAS no reconhecimento das necessidades da família e dos seus membros. Por exemplo, o convívio familiar ser entendido como um aspecto da segurança social e até mesmo como um direito, seguindo as orientações do ECA, que veda a retirada do poder familiar em caso de carência de meios materiais da família, é um dos aspectos de valorização da família. No entanto, capitalizar esses avanços no discurso num momento de reorganização dos sistemas de proteção social e conseqüente desmonte dos equipamentos diretos de proteção da família, apostando no co-financiamento Estado-sociedade e na família como instituição para subsidiar os seus próprios meios de sobrevivência é, no mínimo, discutível pelo seu caráter oportunista. 


\section{Conclusão}

Entendemos que a política social refere-se ao Estado interventor acerca das expressões da questão social. No caso, a política de desobrigação no enfrentamento da questão social implica o estreitamento de novas formas de solidariedade na relação Estado e sociedade e Estado e família, que se expressam de forma diversificada nos programas de enfrentamento da pobreza. As políticas públicas deixam um rastro de insuficiências quando direcionam os programas de atenção e proteção pela perspectiva da parceria solidária e o privilegiamento de condições extremas de vulnerabilidade e risco social, apesar dessa situação atingir parcelas significativas da população.

Podemos concluir que as políticas públicas se aproximam do modelo familista, entendido quando essas políticas consideram que as unidades familiares devem assumir a responsabilidade principal pelo bem-estar social de seus membros (Mioto; Campos; Lima, 2006).

Finalizando, apoiados, em parte, na literatura consultada, indicamos alguns desafios a serem superados e enfrentados no trabalho direto com famílias, na perspectiva de garantia dos seus direitos:

- Superar a armadilha do modelo pensado como orientador da ação. Nessa perspectiva a ação é normativa, com privilegiamento das formas perversas e tirânicas de se pensar a família. O trabalho com as famílias (Szymanski, 1992) evidencia que o desempenho delas não depende de sua organização, mas da qualidade do vínculo, das relações afetivas. Metodologicamente enfatizamos o conhecimento de fato do cotidiano da "família vivida", mapeando suas estratégias de sobrevivência e demandas. 
- Conhecer as demandas das famílias implica o aprofundamento teórico em várias temáticas, muitas tratadas por autores diferenciados, como a violência doméstica e familiar contra a mulher, abuso sexual contra crianças e adolescentes, população em situação de rua, dependência de droga etc. Apontamos, ainda, a necessidade de implementar políticas específicas para grupos-alvo específicos, contemplando a diversidade de demandas e de segmentos sociais.

- Focalizar, prioritariamente, indivíduos e grupos em situação de Conhecer vulnerabilidade e risco social, mapeando a sua heterogeneidade para ações específicas.

- Superar a visão de família apreendida enquanto sujeitos individuais ou a partir do "membro-problema". A família não pode ser vista pelo retrovisor, como coadjuvante para o atendimento individual. O foco é a família enquanto grupo de relações de mutualidades e reciprocidades, incluindo questões polêmicas, como a paternidade responsável, por exemplo.

- Não centrar as responsabilidades na mulher, sobrecarregando-a. Essa perspectiva implica romper com uma herança há muito sedimentada nas representações sociais acerca da família e da posição da mulher nesse núcleo.

- Ampliar o âmbito de ação na perspectiva do trabalho em rede com os demais programas de proteção e atenção à família.

Concluímos afirmando que a família tem uma posição importante no processo de reprodução e reposição da vida social e é um sujeito coletivo a ser cuidado. As mudanças sociais das últimas décadas e em curso estão exigindo muitas respostas das famílias, nem sempre possíveis, seja pelas 
carências seja pelas dificuldades de lidar com os desafios diários relativos, por exemplo, ao exercício da autoridade, ao uso de limites, à convivência geracional etc. As pressões do cotidiano sobre as famílias nos cuidados e proteção dos seus membros são intensas e, portanto, a dimensão real de parceria com o Estado implica cuidar da família para que esta cuide dos seus membros. Esta objetivação depende do seu reconhecimento e fortalecimento como um sujeito de direitos e sua inclusão como uma prioridade nas políticas públicas.

\section{Referências}

AMARAL, Sueli G. Pacheco do; TOLEDO, Laisa Regina Di Maio Campos. Trabalho e a feminização da pobreza. Presença da Mulher, São Paulo, v. 15, n. 40, out./dez. 2001.

ARIÈS, P. História social da criança e da família. Rio de Janeiro: Zahar, 1978.

CAMPOS, Marta Silva; MIOTO, Regina C. T. Política de Assistência Social e a posição da família na política social brasileira. Ser Social, Brasília, v. 1, n. 1, 1998.

CARDOSO, Ruth. Prefácio. In: PERSPECTIVAS antropológicas da mulher. Rio de Janeiro: Zahar, 1985. v. 4.

CARVALHO, Luiza. Família chefiadas por mulheres: relevância para uma política social dirigida. Serviço Social e Sociedade, São Paulo, v. 19, n. 57, jul. 1998.

CHAUÍ, Marilena. Participando do debate sobre mulher e violência. In: PERSPECTIVAS antropológicas da mulher. Rio de Janeiro: Zahar, 1984. v. 4, p. 23-62.

CORREA, Marisa. Repensando a família patriarcal brasileira. Cadernos de Pesquisa, São Paulo, n. 37, maio 1981.

DAMATTA, Roberto. A casa e a rua: espaço, cidadania, mulher e morte no Brasil. São Paulo: Brasiliense. 1985.

D'INCAO, Maria Ângela. Amor e família no Brasil. São Paulo: Contexto, 1989. 
ENGELS, F. El origen de la família, la propiedad privada y el Estado. Moscou: Progreso, 1970.

FIGUEIRA, Sérvulo A. Apresentação. In: FIGUEIRA, Sérvulo A. (Org.). Uma nova família? 0 moderno e o arcaico na família de classe média brasileira. Rio de Janeiro: Zahar, 1987.

FREYRE, Gilberto. Casa grande \& senzala. 9. ed. Rio de Janeiro: José Olímpio, 1977.

GIDDENS, Anthony. A transformação da intimidade. São Paulo: UNESP, 1992.

HABERMAS, J. A família burguesa e a institucionalização de uma esfera privada referida à esfera pública. In: CANEVACCI, Massimo (Org.). Dialética da família. São Paulo: Brasiliense, 1984.

HELLER, Agnes. A concepção de família no Estado de Bem-estar Social. Serviço Social e Sociedade, São Paulo, v. 8, n. 24, ago. 1987.

. Para mudar a vida. São Paulo: Brasiliense, 1982.

KOWARICK, Lúcio. Cidade \& cidadania: cidadão privado e subcidadão público. São Paulo em Perspectiva, São Paulo, v. 5, n. 2, abr./jun. 1991.

LASH. Christopher. Refúgio num mundo sem coração: a família santuário ou instituição sitiada? Rio de Janeiro: Paz e Terra, 1991.

MESTRINER, Maria Luiza. O Estado entre a filantropia e a assistência social. São Paulo: Cortez, 2001.

MIOTO, Regina Célia Tamaso, CAMPOS, Marta Silva; LIMA, Telma C. Sasso. Quem cobre as insuficiências das políticas públicas? Contribuição ao debate sobre a família na provisão de bem-estar social. Revista de Políticas Públicas, São Luis, v. 10 n.1, jan/jun. 2006.

POSTER, M. Teoria crítica da família. Rio de Janeiro: Zahar, 1979.

REIS, José Roberto Tozoni. Família, emoção e ideologia. In: LANE, Sílvia; CODO, W. (Orgs.). Psicologia Social: o homem em movimento. 7. ed. São Paulo: Brasiliense, 1989.

ROMANELLI, Geraldo. Autoridade e poder na família. In: CARVALHO, Maria do Carmo Brant de. (Org.). A família contemporânea em debate. São Paulo: Educ, Cortez, 1995. 
SAFFIOTI, Heleieth I. B. Gênero, patriarcado, violência. São Paulo: Fundação Perseu Abramo, 2004.

SALEM, Tânia. Mulheres faveladas: com a venda nos olhos. In: PERSPECTIVAS antropológicas da mulher. Rio de Janeiro: Zahar, 1980. v.1.

SARTI, Cynthia. A família como espelho: um estudo sobre a moral dos pobres. São Paulo: Autores Associados, Fapesp, 1996.

SEADE (Fundação Sistema Estadual de Análise de Dados). Famílias chefiadas por mulheres: pesquisa de condições de vida na Região Metropolitana de São Paulo. São Paulo: SEADE, 1994.

SENNETT, Richard. O declínio do homem público: as tiranias da intimidade. 3. ed. São Paulo: Companhia das Letras, 1993.

SZYMANSKI, Heloísa. Trabalhando com famílias: caderno de ação. São Paulo: IEE/PUC-SP, 1992.

TOLEDO, Laisa R. Di Maio Campos. As multidimensionalidades do feminino no jogo do poder no campo da sexualidade: um estudo na perspectiva da identidade. Tese (Doutorado) - Pontifícia Universidade de São Paulo (PUC-SP), 1995.

. Famílias chefiadas por mulheres em situação de vulnerabilidade social: uma demanda a ser enfrentada. Comunicação apresentada no XI Congresso Brasileiro de Assistentes Sociais (CBAS), 2004.

. Violência doméstica e familiar: uma demanda a ser enfrentada. PUC Viva, São Paulo, v. 8, n. 30, abr./jun. 2007. Disponível em: $<$ http://www.apropucsp.org.br/revista/r30_r11.htm>.

VELHO, Gilberto. Individualismo e cultura. Rio de Janeiro: Zahar, 1981. 